The Effect of Social Entitlement

Programs on Private Transfers:

New Evidence of Crowding Out

Kristopher Gerardi and Yuping Tsai

Working Paper 2010-15

September 2010

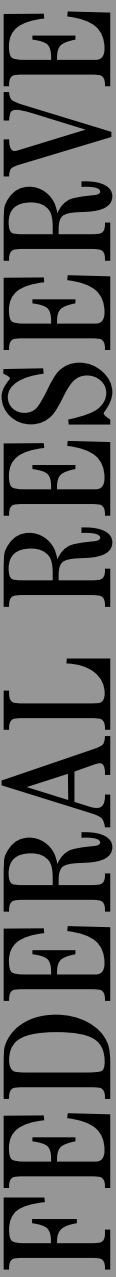




\title{
The Effect of Social Entitlement Programs on Private Transfers: New Evidence of Crowding Out
}

\author{
Kristopher Gerardi and Yuping Tsai
}

\section{Working Paper 2010-15}

September 2010

\begin{abstract}
This paper exploits a natural policy experiment to directly identify the crowding out effects of public transfers on the incidence and level of private transfers. The introduction of a large social security program in Taiwan is used to estimate the effect of an exogenous increase in government transfer payments to the elderly on the private transfer behavior of their adult children. Using an instrumental variables strategy that accounts for the endogeneity of receiving public transfers, the empirical results show strong evidence of crowding out on the extensive margin (the probability of providing a positive transfer) and weaker evidence of crowding out on the intensive margin (the amount of the transfer conditional on it being positive).
\end{abstract}

JEL classification: H53, H55, H31

Key words: private transfers, crowding out

The authors thank Kevin Lang, Chris Cunningham, and Chris Foote for helpful comments and discussions. The views expressed here are the authors' and not necessarily those of the Federal Reserve Bank of Atlanta or the Federal Reserve System. Any remaining errors are the authors' responsibility.

Please address questions regarding content to Kristopher Gerardi, Research Department, Federal Reserve Bank of Atlanta, 1000 Peachtree Street, N.E., Atlanta, GA 30309-4470, 404-498-8561, Kristopher.gerardi@atl.frb.org, or Yuping Tsai, Spelman College, 350 Spelman Lane S.W., Atlanta, GA 30314-4399, ytsai@spelman.edu.

Federal Reserve Bank of Atlanta working papers, including revised versions, are available on the Atlanta Fed's Web site at frbatlanta.org/pubs/WP/. Use the WebScriber Service at frbatlanta.org to receive e-mail notifications about new papers. 


\section{Introduction}

Determining the impact of public transfer programs on private transfer behavior is a key issue from both a research and policy perspective. If public transfers largely crowd out private transfers, then the welfare impact of social redistributive programs will be smaller than perceived. Economic theory is ambiguous in its predictions about crowding out. The altruism model developed in the seminal papers of Barro (1974) and Becker (1974), predicts essentially complete crowding out. The model focuses on transfers from parents to children, but can be applied equally well to transfers from adult children to their elderly parents. In the model, the child's utility is included in an altruistic parent's utility function, which gives the parent an incentive to support the child. The core of the altruism model is the prediction of redistribution neutrality, which posits that the parents will adjust their transfer behavior in response to changes in the child's income. For example, an increase in the child's income due to welfare subsidies from the government will lower the amount of parental transfers. If Ricardian Equivalence holds and the government subsidy is financed by a tax on the parents' income, then the parents will reduce their transfer exactly by the tax amount, implying complete crowding out.

In contrast to the altruism model, the exchange model of Bernheim et al. (1985) and Cox (1987) argues that a child's services to the parents, such as contacts and visits, are at least in part, financially motivated, as the child expects monetary compensation. In this model, the amount of transfers could be a positive or negative function of the child's income. As the child's income increases, the opportunity cost of services increases, and thus, the amount of expected compensation for the services increases. In such a setting, the relationship between the child's income and the amount of parental transfers is not clear. It could be positive if the parents' demand for services is inelastic, as they would need to increase transfer payments to the child in order to receive the same level of services. If this were the case, government subsidies would increase the amount of private transfers received and thus, there would be no crowding effect. On the other hand, if the demand for services is highly elastic, then parents' demand would fall along with 
monetary compensation, which would lead to crowding out. ${ }^{1}$

As a result of the ambiguous effect of crowding out predicted by theory, a relatively large empirical literature has focused on the estimation of both the sign and magnitude of the crowding-out effect of public transfer programs. However, due to data limitations, most empirical studies have not been able to directly measure the crowding out effect of public redistribution programs. Most studies in this literature have attempted to indirectly measure the impact of such programs on beneficiaries by studying the response of private transfers to changes in the recipient's level of income. The results from these papers, however, are not consistent. Some studies have found a positive income effect on private transfers (Cox, 1987; Cox, 1990; Cox and Rank, 1992) while others have found a small, negative effect (Altonji et al., 1997; Cox and Jappelli, 1990; Hochguertel and Ohlsson, 2009; Kazianga, 2006; McGarry and Schoeni, 1995; McGarry, 2000).

In this paper we exploit a natural policy experiment and a novel dataset to directly identify the crowding out effect of a large social welfare program on the incidence and level of private transfers. The setting of our study is the country of Taiwan, which implemented a large social security program in 2002 called the Senior Citizen Welfare Living Allowance that covered a significant fraction of the elderly population. Using the parameters of this program, and a nationally representative dataset that contains information on monetary transfers from children to elderly parents before and after the introduction of the program, along with a rich set of socio-demographic and financial variables to alleviate potential bias from omitted variables, we are able to estimate the effect of an exogenous increase in government transfer payments to the elderly on the private transfer behavior of their adult children. The empirical results show strong evidence of crowding out on the extensive margin (the probability of providing a positive transfer), and weaker evidence of crowding out on the intensive margin (the amount of the transfer conditional on it being positive). According to the estimates, the probability that an adult child provides monetary transfers to his or her parents decreases by $50 \%$ if

\footnotetext{
${ }^{1}$ For a more detailed discussion of microeconomic models of family transfers, see Laferrère and Wolff (2006).
} 
the parents receive public assistance. Taking into account the intensive margin, we find complete crowding out of private transfers, although the intensive margin results are imprecisely estimated. In addition, we find that the crowding out effect is substantially stronger for children who live with their parents and somewhat weaker for male children.

There are only a handful of previous studies in the literature that attempt to directly identify the crowding out effect of public redistribution programs, and they have found mixed results. Cox and Jimenez (1992) was one of the first of these studies. Using data from Peru, they found evidence that households receiving social security income were significantly less likely to receive positive transfers from children. ${ }^{2}$ However, the effect of receiving social security income on the amount of transfers received (conditional on receiving a positive transfer) was small and positive. The authors speculated that the estimated positive effect was due to the omission of donor income, which created an upward bias. Rosenzweig and Wolpin (1994) examined the crowding out effect of benefits from the Aid to Families with Dependent Children (AFDC) on shared housing and financial support from parents. Their findings suggested only a small trade-off between public assistance and parental support.

There is a serious econometric issue that all of these studies face however: the lack of income data for both the recipient and donor and the potential endogeneity of eligibility. An individual's decision to apply for government transfer programs and the size of the benefits received likely depends on whether the individual is expecting or receiving private transfers. In turn, the amount of private transfers received depends on the income of both the recipient and the donor, but that information has proven difficult to obtain. Rarely has a dataset had information regarding both variables, and thus, omitted variable bias is an important concern in these studies. Most recent papers in this literature have focused on this issue. Cox and Jakubson (1995) constructed a proxy for donor income and used an IV approach to address the endogeneity of various sources of public transfer income. Using the 1979 President's Commission on Pension

\footnotetext{
${ }^{2}$ At the sample means, receiving social security income reduced the probability of transfer receipt by 8 percentage points.
} 
Policy Survey, they found that public transfers only marginally reduce private transfers. Schoeni (2002) used the 1988 wave of the Panel Study of Income Dynamics (PSID) to examine the effect of unemployment benefits on private transfers. He used state-specific policy parameters to instrument for the eligibility of receiving unemployment benefits and found a sizeable crowding out effect: a one dollar increase in unemployment income reduced family transfers by about 40 cents. Moreover, the estimated crowding out effect obtained using IV estimation was significantly larger than the effect obtained using simple ordinary least-squares (OLS) estimation, and thus the endogeneity of participation in the unemployment benefits program led to an underestimate of the crowding out effect.

Jensen (2004) analyzed how an expansion in pension benefits in South Africa affected the size of remittance payments given to elderly individuals. To identify the effect, he applied a differences-in-differences-in-differences approach, which used pension discontinuities at gender differentiated age thresholds along with time-series variation in pension benefits. His estimates imply that a one dollar increase in pension income leads to a $0.25-0.30$ cent reduction in private transfers received from children. The most recent study in the literature, and the analysis closest in methodology to ours, was conducted by Juarez (2009). Juarez also exploited a policy change to address the endogeneity of public transfers, focusing on a public program introduced in Mexico City that provided monthly transfers to individuals aged 70 years or more. Juarez used an IV Tobit regression specification to estimate the effect, and found strong evidence of crowding out (an additional peso of income reduced total cash transfers by 86 cents). ${ }^{3}$

Like Jensen (2004) and Juarez (2009), this study uses an exogenous policy change to identify the crowding out effect of public redistribution programs on private transfer payments to the elderly. But, in our opinion, this paper has some advantages over the previous literature. First, the dataset used in this study (the Panel Study of Family Dynamics, or PSFD) is nationally representative, and the policy change was to a large

\footnotetext{
${ }^{3}$ The instruments for individuals' income without private transfers include triple interaction terms of a dummy for being at least 70 years old, with a dummy for Mexico City resident, and a dummy for each year after the program started (2002 and 2004).
} 
percentage of the elderly Taiwanese population (aged 65 and above). In contrast, the data used in Jensen (2004) was collected in Venda, a rural and low-employment area in South Africa that is likely not representative of populations in more developed countries. The public transfer program studied by Juarez (2009) only affected elderly residents in Mexico City, and because of budget constraints, the program only covered poor neighborhoods in its early stages. A second advantage is the fact that we are able to precisely identify both the donor and the recipient of private transfers. The respondents in the PSFD are the donors (adult children), who provide detailed information regarding monetary transfers to their elderly parents. Moreover, the respondents report whether they share housing with their parents, and thus, we are able to analyze the effect of the government transfer program on both inter- and intra-family transfers. ${ }^{4}$ The PSFD data also allow us to control for numerous socio-demographic characteristics of both the donors and recipients. Finally, in addition to these advantages, our paper shares one of the important advantages of the Juarez study: the crowding effect is evaluated at the individual level as opposed to the household level. As Juarez explains, many studies have rejected the unitary model of the household. If households do not pool their income together, then the effect on the outcome variable will depend on whose income increases within the household.

The rest of the paper is organized as follows: Section 2 provides a discussion of the background of the Senior Citizens Welfare Living Allowance, which is the social insurance program that we focus on in this paper; section 3 provides a detailed discussion of the PSFD data and our empirical strategy; section 4 presents the estimation results for the full sample as well as for various subsamples of interest; and section 5 concludes.

\footnotetext{
${ }^{4}$ In Juarez's data, the role of respondents are receivers (the elderly) and there is no information on the source of private transfers and on the transfers between household members. Intrafamily transfers might be important given that only $25 \%$ of elders live alone in Mexico City.
} 


\section{Background}

\subsection{Aging Population}

Over the past few decades Taiwan has experienced a rapidly aging population. In 1993, the population above 65 years old reached $7 \%$ of the total population, which according to the United Nations, is a benchmark of an old age society. Since the early 1990s, the elderly population has steadily increased. According to the Ministry of the Interior (MOI), by 2009 it had reached 2.4 million, accounting for approximately $10.6 \%$ of the total population.

In order to meet the social, physical and economic needs of its growing elderly population, over the past decade the Taiwanese government has expanded and introduced various social benefit programs. These include the expansion of medical allowances and stabilized living allowances, and the introduction of several insurance and pension programs. In October 2008, the government combined several programs for the elderly and implemented the National Pension Program with the goal of increasing the standard of living of its retired population. Before the introduction of these programs, the elderly population in Taiwan depended primarily on their children for financial support. In 1999, about $73 \%$ of elders lived with their children and about $52 \%$ reported that children were their main source of income (MOI). Although more and more of the elderly choose to live alone and the introduction of these government programs has alleviated some of their financial stress, as of 2005 , approximately $61 \%$ of seniors were still living with their children and $53 \%$ relied primarily on their children for financial support. ${ }^{5}$

\subsection{Senior Citizens Welfare Living Allowance}

The precursor to the National Pension Program was the Senior Citizen Welfare Living Allowance, which was implemented in 2002. This program, which was developed for senior citizens who were not covered by other social insurance programs at the time,

\footnotetext{
${ }^{5}$ About $33 \%$ of Taiwanese seniors in 2005 reported that their primary source of income came from government transfers.
} 
is the focus of our study. Citizens who were at least 65 years old and who resided in Taiwan for more than 183 days per year for the previous three years qualified for the program. ${ }^{6}$ Beneficiaries of the program received a monthly transfer of NT $\$ 3,000$ (approximately $\$ 100$ dollars), which represents approximately $10 \%$ of the average monthly income for qualified seniors in our data. There was a cap on beneficiaries' gross income of NT $\$ 5,000,000$, and a cap on the value of land and property owned of NT $\$ 500,000$. However, these thresholds are quite high relative to the distribution of senior income and wealth in Taiwan. About $81 \%$ of seniors in our data have total income lower than the cap on gross income. Moreover, in the 2004 wave of the PSFD, about $81 \%$ of respondents reported that the property values owned by their parents were below the cap. Thus, eligibility for the Allowance program depends primarily on citizens' age.

The program officially took effect on May 22, 2002, but the allowance was made retroactive to January 1, 2002 for seniors who applied before August 31, 2002. Potential beneficiaries had to file applications to their local government office, which then verified the application documents and submitted them to the Bureau of Labor for further examination and official approval. ${ }^{7}$ Upon approving an application, the government deposited the monthly allowance directly to the beneficiary's bank account. ${ }^{8}$ Thus, transaction costs after approval are nearly zero. The program covered approximately 425,000 seniors in 2002, and by 2007, that number nearly doubled to almost 850,000 , which accounted for approximately $35 \%$ of the entire elderly population in Taiwan. However, it accounted for a much larger percentage of the non-farming elderly population as the Senior Farmers Welfare Allowance, which covered elderly farmers, accounted for approximately $29 \%$ of the senior Taiwanese population. Seniors were not allowed to participate in both pro-

\footnotetext{
${ }^{6}$ Citizens who were excluded from the program included: those that were receiving government provided shelter; those that were receiving a living subsidy for being physically and/or mentally disabled; senior farmers and veterans receiving a welfare allowance; extremely poverty-stricken senior citizens that were receiving a welfare subsidy; those in the military that were receiving a lifetime living subsidy and a retirement benefit; those that worked for a government agency (including public schools); and finally those that were imprisoned.

${ }^{7}$ This process shall not take more than 20 days.

${ }^{8}$ The allowance was cash, and thus there was no restriction on how a beneficiary could spend the transfer payment.
} 
grams. Thus, the Senior Citizen Welfare Living Allowance accounted for roughly $50 \%$ of the non-farming senior population.

\section{Data and Empirical Strategy}

We construct our sample from the PSFD, which is a nationally representative, longitudinal survey that was conducted in Taiwan from 1999 to 2006. The PSFD constructed their survey sample using a three-stage stratified random sampling technique. The first wave of the sample included individuals born between 1953 and 1964. In 2000, respondents born between 1934 and 1954 were added to the main sample. The PSFD focused on features of the Taiwanese family that included the interaction among family members, family resource allocation, and living arrangements. Most importantly, for our purposes, it collected information on intergenerational transfers between parents and children. ${ }^{9}$

The PSFD asks respondents two questions about the amount of monetary assistance given to their parents. The first question reads "During the last year, did you provide your parents loans, living expenses and red envelope?" 10 The second question reads "If yes, what was the monthly amount?" With the responses to these two questions we are able to see whether respondents gave positive monetary transfers to their parents, and if so, the monthly amount given. Unfortunately, there is less information about the quantity of public transfers received by respondents' parents. The respondents are only asked if their parents received social welfare benefits during the last year. In addition this question was only asked in the 2002, 2004, and 2006 surveys. Thus, we will only be able to study the effect on private transfers of a parent receiving a positive amount of public transfers, rather than the effect of a marginal increase in public transfers, and we will be constrained to only using the surveys conducted in 2002, 2004, and 2006.

\footnotetext{
${ }^{9}$ In 2000, the survey interviewed the children (aged 16 to 22 ) of the main respondents with follow-up interviews conducted every two years. Starting from 2003, children of the main respondents over the age of 25 were also included as part of the main sample.

${ }^{10}$ In Taiwan and other East Asian societies, a red envelope is a monetary gift which is given during holidays or special occasions.
} 
Despite this one drawback, the PSFD has many advantages over other datasets used in this literature. It contains fairly detailed information on the demographic and economic characteristics of respondents, including age, gender, marital status, educational levels, health status, employment status, total family income, and living arrangements (in particular, whether the respondent lives with his or her parents). The PSFD also asks respondents about basic demographic characteristics of their parents, including their age, educational attainment, whether they receive retirement income, whether they take care of grandchildren, and whether one of the parents has a serious health problem. Thus, we are able to control for characteristics of both the donor (adult children) and the recipient (elderly parent).

We pool together the 2002, 2004, and 2006 PSFD surveys, which provides 12,343 observations. However, we do not use all of these observations in our baseline sample because of the following restrictions that we impose: First, we restrict our sample to respondents who have at least one living parent. Second, we impose a minimum parental age requirement of 50 years and a minimum age requirement of 25 for the (child) respondent, because we want to confine our analysis to adult children who are economically independent of their parents. We also impose a parental maximum age limit of 95, a maximum respondent age of 65 , and drop 82 observations that reported a monthly transfer amount greater than NT\$50,000 $(\$ 1,600)$. After excluding observations with missing values for our chosen set of control variables that we describe below, we are left with a final sample of 4,864 individuals.

Table 1 lists summary statistics for the full sample of respondents (column 1), while in Table 2 we break the sample into the respondents who report that their parents receive government support and the respondents who report that their parents do not receive any government assistance. The top panel in both tables lists the characteristics of the parents while the bottom panel lists the characteristics of the respondents. The variables included in the tables are all included in our set of control variables ( $x_{i}$ below).

Most of the respondents in our sample are middle-aged (average of 42 years), but 
there is a lot of variation in age as the standard deviation is 10 years. Approximately $69 \%$ of respondents reported giving their parents cash transfers during the previous year, and the average monthly amount of transfers given, for those who gave something, was NT\$5,101 (\$160). ${ }^{11}$ The high incidence of private transfers is consistent with our expectations. Transfers from children have traditionally been the primary income source for the elderly due to the social culture in Taiwan and the lack of a national pension program. Thus, unlike most existing studies in this literature, we focus on monetary transfers from children (donors) to parents (receivers).

In the full sample, approximately $42 \%$ of parents receive government social benefits. According to Table 2, there is a significant difference in private transfer behavior between the respondents whose parents receive social benefits and those whose parents did not receive social benefits. Parents that receive government assistance are about 6 percentage points more likely to receive private transfers from their children compared to parents that do not receive public transfers. This is suggestive of a crowding in effect as opposed to crowding out. However, differences across the two groups in the amount of transfers received (conditional on receiving something), suggests a crowding out effect. Respondents whose parents receive government assistance donate NT $\$ 1,800$ less compared to those whose parents do not receive government help. Of course these numbers are simply raw averages, and should be treated with caution in light of the endogeneity issues discussed above. There are also significant difference in other attributes across these two groups. Parents who receive government assistance are considerably older, in worse health, have lower education, and are less likely to receive retirement income. Respondents with parents that receive government support are considerably older, more likely to be married, are in worse health, have lower education, and are less likely to live with their parents.

In this paper we are interested in estimating the crowding out effect of public transfers on both the intensive and extensive margins of private transfer reception. To estimate

\footnotetext{
${ }^{11}$ Most respondents (94\%) do not report receiving transfers from their parents (not shown in tables).
} 
the effect on the extensive margin we use a probit specification:

$$
\operatorname{Pr}\left[D_{i}=1 \mid G_{i}, x_{i}\right]=\Phi\left(\beta_{1} G_{i}+x_{i}^{\prime} \beta_{2}\right)
$$

where $D_{i}$ takes the value of 1 if respondent $i$ provides cash transfers to his or her parents and 0 otherwise, $G_{i}$ takes the value of 1 if the respondent's parents receive government transfers and 0 otherwise, $x_{i}$ is a vector of control variables that include the characteristics of both the respondent and the parent(s) listed in Tables 1 and 2 , and $\Phi(\cdot)$ is the cumulative distribution function of the standard normal distribution.

To estimate the effect on the intensive margin we use a Tobit specification to account for the large fraction of respondents that do not provide any transfers to their parents:

$$
F_{i}=\max \left[0, \gamma_{1} G_{i}+x_{i}^{\prime} \gamma_{2}+\varepsilon_{i}\right]
$$

where $F_{i}$ represents the amount of private transfers that respondent $i$ gives to his or her parents.

The coefficients of interest are $\beta_{1}$ and $\gamma_{1}$, which represent the effect of government assistance on the probability of receiving private transfers and on the amount received. The estimation of equations (1) and (2), however, is problematic due to the potential endogeneity of parents' welfare status, $G_{i}$. First, parents who expect to receive or are receiving monetary support from their children may have less of an incentive to apply for government assistance programs. Second, unobservable characteristics may be correlated with both the receipt of government transfers and the receipt of private transfers.

For example, we do not have information regarding parents' income. Seniors with low financial resources are more likely to qualify for government assistance programs, and are more likely to apply for such programs even conditional on being eligible. At the same time parents with low financial means are more likely to receive assistance from their children. This combination would create an upward bias on the estimates of $\beta_{1}$ and $\gamma_{1}$, 
and cause us to underestimate the crowding out effect of public transfers. ${ }^{12}$

To deal with this endogeneity problem, we form a set of instruments based on the introduction of the Senior Citizen Welfare Living Allowance. ${ }^{13}$ As we discussed above, beginning in 2002, Taiwanese citizens older than 65 years old have benefited from the Allowance program. Thus, we expect parents' welfare status, $G_{i}$ to be positively correlated with the introduction of the program in 2002. We have one year of data (2001) before the introduction of the program, and two years of data after the introduction (2003 and 2005). Figure 1 shows the probability of parents receiving government transfers by age and year. ${ }^{14}$ Note that the PSFD survey asks about private transfers given and received and public transfers received during the previous year. Thus, the numbers in Figure 1 represent the probability of receiving public transfers in the year prior to the survey year (so the 2002 survey asks about transfers in 2001). In addition, this implies that age of eligibility for the Allowance program is actually 66 in the survey years. The figure shows the fraction of parents that received government assistance in the 2002 survey was basically linearly increasing in age, from 0 at age 63 to about 0.6 at age 75 , with no discernible jump at age 66 . In contrast, there is a more pronounced, discrete jump from the age of 65 to 66 in both the 2004 and 2006 surveys. The jump is much larger in 2006 (slightly less than 0.1 to 0.4 ) compared to 2004 (0.1 to 0.25$)$. Differences between the 2004, 2006 surveys and the 2002 surveys remain persistent beyond the age of 66 at about 20-30 percentage points. ${ }^{15}$

\footnotetext{
${ }^{12}$ The bias could also go the other way. For example, parents with a disadvantaged background (lower wealth and lower income) may be more likely to apply for social benefit programs, and their adult children, who grew up in the same disadvantaged environment, are likely to have fewer resources to support their parents in old age. Since we do not have information on the amount of wealth of either the respondents or the parents, estimates of $\beta_{1}$ and $\gamma_{1}$ would be biased downward and we would estimate a crowding out effect that is too large. However, we do have information on the income levels of the respondents, which should somewhat alleviate this bias.

${ }^{13}$ With our data, we could also try to address the endogeneity problem using a fixed-effects estimator since many individual characteristics are likely to remain constant over a short time horizon like our 5-year period. However, parents' income and the expectation of receiving private transfers could still change across years, and the longitudinal dimension of our data is only 3 years, which is too short to perform a precise fixed-effects estimation.

${ }^{14}$ Parents' age is defined as follows: if both parents are alive, we set the age equal to the maximum of the two. If the respondent has only one living parent, we set the age equal to the age of the living parent.

${ }^{15}$ While we cut the graph off at age 75 to focus on the discontinuity at age 66 , the difference remains
} 
Figure 1 provides strong evidence that the Allowance program significantly increased the fraction of elderly Taiwanese citizens that received government transfers. We use the variation in the receipt of social benefits from the Allowance program to identify the crowding out effect of public transfers. We use the parameters of the Allowance program - parents' age and the year that the Allowance program took effect, 2002- to generate instruments for the receipt of government transfers, $G_{i}$. Specifically we form two instrumental variables: interaction terms between a dummy variable indicating that at least one parent is over the age of 65 and the two survey years after the implementation of the Allowance program, 2004 and 2006.

We use an IV probit to estimate the crowding out effect on the extensive margin of private transfer receipt and an IV tobit to estimate the crowding out effect on the intensive margin. ${ }^{16}$ The first stage regression for both models, is

$$
G_{i}=\delta_{0}+\delta_{1} x_{i}+\delta_{2} Z_{i}+\eta_{i}
$$

where $Z_{i}$ is the vector of instruments, $x_{i}$ is the vector of controls listed in Tables 1 and 2 , and equations (1) and (3) as well as equations (2) and (3) are jointly estimated by maximum likelihood.

Our identifying assumption is that the parameters of the Allowance program (age requirement and year implemented) only affect private transfer behavior indirectly through their effect on whether a senior receives public assistance, $G_{i}$, and therefore, are not correlated with any unobserved variables that affect private transfer behavior (the residuals in equations 1 and 2). Specifically, we are assuming that no other government program or policy targeted at the senior population (above 65) that may also have affected private

\footnotetext{
through the maximum age in our sample of 95.

${ }^{16}$ We chose to use an IV strategy as opposed to a pure differences-in-differences-in-differences strategy for several reasons. First, we have information on whether or not elderly parents receive public transfers, and by using the variation in this variable created by the parameters of the Allowance program, we are able to more directly address the crowding out question compared to a differences-in-differencesin-differences design. In addition, there appears to be significant dissimilarities between the treatment group (adult children with parents older than 65 years old) and control group (adult children with younger parents). The identification assumption inherent in a differences-in-differences strategy is likely to be violated because the time-trend in transfer behaviors between these two groups may be different.
} 
transfer behavior was implemented at the same time as the Allowance program. To our knowledge, no such program exists. ${ }^{17}$

As we noted above, our vector of control variables $x_{i}$ is composed of the demographic and income variables in Tables 1 and 2, and in addition includes a set of year dummies to control for aggregate shocks that might impact private transfer behavior and the fraction of seniors that seek government assistance. ${ }^{18}$

\section{Results}

Tables 3 and 4 present the estimated effects of receiving public transfers on the extensive and intensive margins of private transfer behavior, respectively. As discussed above, we use a probit specification to estimate the crowding out effect on the extensive margin, and a Tobit specification to estimate the crowding out effect on the intensive margin. These results are reported in the first column of the tables. In the second column, we report the IV estimates that address the potential endogeneity of receiving public transfers. We also present OLS and linear two-stage least squares (2SLS) estimates as robustness checks. For brevity, we report only the estimated coefficients and marginal effects associated with the receipt of public transfers and the coefficient estimates associated with our instruments in the first-stage regressions.

According to the estimation results reported in column 1 of Table 3, parents that receive social benefits are considerably more likely to receive monetary transfers from their children. The estimated marginal effect is statistically significant at the $1 \%$ level

\footnotetext{
${ }^{17}$ A less important consideration is whether the Allowance program is correlated with the income of seniors (which we do not observe) based on income eligibility requirements. If so, then our instruments would be less powerful as a smaller fraction of the elderly Taiwanese population would qualify for the program. However, from our detailed discussion of the program in section 2.2 above, the income cap that defines eligibility into the program is quite high relative to the distribution of income of senior Taiwanese citizens, so that the income cap should not bind for the vast majority of parents in our sample.

${ }^{18}$ In addition, we tried including the number of siblings, number of brothers, number of sisters, the number of times visiting parents in a year, and a set of region dummies, but because they do not effect our estimates (and are not statistically significant themselves), we chose to omit them from our baseline specification. We chose our control set, in part, based on the control set used in Juarez (2009). However, we have more demographic information than Juarez, as she did not have any information about donors, and did not have any information about education levels. She did have information about recipients' income, which we do not have.
} 
and the magnitude is not trivial. Evaluating the marginal effect at the means of all other explanatory variables, receiving social benefits increases the likelihood of receiving transfers from children by approximately $5 \%$. This result suggests that public transfers crowd in private transfers. The IV estimates reported in column 2, however, reveal evidence of significant crowding out. The estimated probability of providing monetary assistance to a parent (or parents) falls significantly if the parents receive government assistance. According to the estimated marginal effect, the probability of an adult child providing monetary transfers to his or her parents decreases by about $50 \%$ if the parents receive public assistance. This is a 55 percentage point decrease compared to the probit estimate in column 1, and strongly suggests that treating the receipt of public transfers as exogenous produces a serious upward bias, and leads to an underestimation of the crowding out effect. As we discussed earlier, the main source of the bias likely comes from the omission of receivers' (parents') income, as well-off parents are less likely to receive monetary support from the government as well as from their children, and poorer parents are more likely to receive assistance from both sources. Finally, the OLS and 2SLS estimates located in columns 3 and 4 are consistent with this interpretation.

The first-stage coefficient estimates associated with the instrumental variables are positive and are statistically significant at the $1 \%$ significance level. These results are consistent with the evidence from Figure 1 that shows the Allowance program had the effect of significantly increasing the number of Taiwanese senior citizens who received social benefits. ${ }^{19}$

Turning to the effect of receiving public assistance on the intensive margin of private transfer behavior, the Tobit estimates in Table 4 reveal a small and statistically insignificant crowding out effect. In contrast, the IV estimates suggest a much larger crowding out effect, although they are only marginally significant. According to the point esti-

${ }^{19}$ The value of the Kleibergen-Paap rk Wald F statistic (14.604) using 2SLS implies that the null of weak instruments is rejected based on Stock and Yogo's (2005) critical values. The Staiger and Stock "rule of thumb" that the F statistic should be at least 10 for weak identification to not be a problem is also satisfied. Moreover, the Hansen J statistic (0.006) over-identification test suggests that the instruments are valid. 
mate, conditional on making a positive transfer, an adult child will reduce monetary support to his or her parents by an average of NT $\$ 2,972$ if the parents receive government assistance. This is almost the full transfer amount from the Senior Citizen Welfare Living Allowance program, but again, the estimated effect is imprecisely measured. If we take into account both the intensive and extensive margins estimates from the Tobit regression, (i.e. including the respondents that stopped providing monetary support to their parents after the introduction of the Senior Citizen Welfare Living Allowance program), the total estimated effect increases by approximately $40 \%$ to NT $\$ 4,161(\$ 130),{ }^{20}$ although this point estimate is also imprecisely estimated. It is important to point out that like the extensive margin results in Table 3, the results in columns 1 and 2 in Table 4 suggest a significant downward bias of the crowding out effect if parents' welfare status is assumed to be randomly assigned.

The coefficient estimates associated with our set of control variables are mostly consistent with our expectations. Respondents who are male, older, married, employed and more educated are considerably more likely to make a transfer to their parents and to make a larger transfer conditional on making a positive one. Moreover, respondents with older parents have a higher probability of making a transfer. On the other hand, the likelihood of assisting parents is significantly lower for respondents who are unhealthy, and who live with their parents. Transfer behavior on both the intensive and extensive margins is considerably lower for respondents whose parents are more educated, and receive retirement income (in addition to any public transfers).

\subsection{Subsample Analysis}

Evidence from the literature suggests that the crowding out effect of public transfers may vary across demographic groups. For example, Cox et al. (2004) found that the crowding out effect is larger for recipients with low income, and Juarez (2009) found a

\footnotetext{
${ }^{20}$ Based on the McDonald and Moffit (1980) decomposition, the decrease in the probability of making a positive transfer is $35 \%$. Due to the limitations of the Tobit model, we chose to perform probit estimation to estimate the effect on this probability.
} 
similar result. In this section, we explore whether the crowding out effect is sensitive to socio-demographic characteristics. To do this, we add interaction terms of an indicator for whether elderly parents receive social benefits and the socio-demographic characteristics of interest to the set of control variables in equations 1 and 2 . We focus on four sociodemographic characteristics: gender, living arrangements (whether the respondent lives with his or her parents), parents' educational attainment (whether at least one of the parents did not finish primary schooling), and childrens' (donors') income (whether the respondent's income is in the lower half of the income distribution). The results are reported in Table $5 .^{21}$

In Taiwanese society, traditionally sons have been the primary caregiver for elderly parents. Therefore, their response to the government transfer program may be different from that of daughters. The estimates from the IV probit models support this prediction, as the crowding out effect of public transfers on the extensive margin is significantly lower for male respondents compared with female respondents. The intensive margin estimates also provide evidence of less crowding out for male respondents, though the effect is not statistically significant.

Unlike the U.S., it is quite common in Taiwanese society for adult children to live with their parents. This is borne out in the data as approximately one-third of respondents in our sample share a home with their parents. The crowding out effect of public transfers is much stronger for these respondents, on both the intensive and extensive margins. One potential explanation for these results is that respondents who live with their parents may have more information about their parents' financial situation and in particular, the specific sources of their income. Thus, it may be the case that children living in separate homes are not as privy to the exact magnitude and timing of public transfers given to their parents, or perhaps they are not even aware that their parents are receiving such transfers in the first place. Another possible explanation is that children who live with their parents may provide more nonmonetary support, such as caring for them when

\footnotetext{
${ }^{21}$ We had difficulty in obtaining convergence for the maximum-likelihood estimator. Thus, we used Newey's two-step estimator with robust standard errors computed by bootstrapping methods.
} 
they are sick, cleaning the home, and preparing food. If this is the case then as parents' financial situation improves as a result of government transfers, they may ask for less monetary support from their children.

While we do not have information regarding the income of parents in our sample, we do have information on their educational attainment, which we expect to be highly correlated with income. However, we find the crowding out effect of public transfers is similar among parents with different levels of educational attainment, as the estimated effects are small in magnitude and are not statistically significant on either the extensive or intensive margin.

Finally, we look at respondents' income. Our hypothesis is that the private transfer behavior of higher income respondents may be less sensitive to the public transfer status of their parents. We find weak evidence supporting such a hypothesis on both the extensive and intensive margin, as the effects are small in magnitude and none of the estimated effects are statistically significant at less than the 10 percent level.

\section{Conclusion}

Overall, we find evidence of a crowding out effect stemming from the introduction of the Senior Citizen Welfare Living Allowance program in Taiwan. According to our estimates, receiving government assistance significantly decreases the likelihood of an elderly Taiwanese citizen receiving monetary support from his or her child. Senior citizens who receive public assistance are approximately $50 \%$ less likely to receive transfers from children compared to senior citizens that do not receive public assistance. ${ }^{22}$ In addition to the crowding out effect on the extensive margin of private transfer provision, we find some evidence of crowding out on the intensive margin. Our point estimates of the crowding out effect on the intensive margin suggests complete crowding out, but are not measured as precisely as our extensive margin estimates. We find that the crowding out

\footnotetext{
${ }^{22}$ Note that this number is evaluated at the means of other explanatory variables. The estimated effects are different for individuals with different attributes.
} 
effect is different across various subsamples of our data, as private transfer behavior is more sensitive to public transfer status for male respondents and for respondents that live with their parents.

These results are somewhat surprising given our knowledge of the social values of the Taiwanese society. Providing for parents in old age has traditionally been the main responsibility of children. Thus, one might expect that transfer behavior of children would be less sensitive to the introduction of a public assistance program relative to other cultures. Our results, however, contrast with this expectation and are consistent with recent findings from other countries, including Juarez (2009). ${ }^{23}$ These results raise concerns regarding the effectiveness of social transfer programs, even in a society where filial duty is highly valued. In addition, consistent with Juarez (2009), we find that treating social welfare status as an exogenous variable creates significant bias and results in an underestimation of the crowding out effect.

Our findings are consistent with the predictions of the altruism model, while they contrast with a commonly parameterized version of the exchange model of private transfer behavior. In the exchange model an increase in the income of recipients of private transfers (parents in our case) leads to an increase in the occurrence of transfers and/or the transfer amount under the assumption that no close market substitutes exist for the services that recipients provide to their donors (adult children in our case). This assumption is likely to hold in the context of this paper, as in Taiwan, most childcare services are provided by relatives or family friends. Due to high costs and uncertain quality, grandparents are usually the main caregivers for their grandchildren. In addition, it is also common for elderly parents to provide housekeeping services for their children, especially when they live in the same household. Thus, if adult children compensate their parents for these services, and demand for these services is inelastic, the exchange model

\footnotetext{
${ }^{23}$ In addition, a recent paper by Lai and Orsuwan (2009) evaluated the crowding out effect of a different social welfare program (Living Allowance for Mid or Low-Income Elders) implemented in 1993 and targeted at relatively poor senior citizens in Taiwan. Using cross-sectional data and a differencesin-differences identification strategy, they found that a one dollar increase in public transfers reduces private transfers by $30-50$ cents.
} 
predicts that private transfers will increase as parents' income increases. Our finding of crowding out contradicts this prediction and thus provides evidence of an altruistic motive behind private transfers. 
[1] Altonji, J.G., Hayashi, F., Kotlikoff, L.J. 1997. Parental altruism and inter vivos transfers: Theory and evidence". Journal of Political Economy 105, 1121-1166.

[2] Barro, R.J. 1974. Are government bonds net wealth?. Journal of Political Economy 82, 1095-1117.

[3] Becker, G.S. 1974. A theory of social interactions. Journal of Political Economy 82, 1063-1093.

[4] Bernheim, B.D., Shleifer, A., Summers, L.H. 1985. The strategic bequest motive. Journal of Political Economy 93, 1045-1076.

[5] Cox, D. 1987. Motives for private income transfers. Journal of Political Economy 95, 508-546.

[6] Cox, D. 1990. Intergenerational transfers and liquidity constraints. Quarterly Journal of Economics 104, 187-218.

[7] Cox, D., Hansen, B., Jimenez, E. 2004. How responsive are private transfers to income? Evidence from a laissez-faire economy. Journal of Public Economics, 88(9): 2193-2219.

[8] Cox, D., Jappelli, T. 1990. Credrationing and private transfers: Evidence from survey data. Review of Economics and Statistics 72, 445-454.

[9] Cox, D., Jimenez, E. 1992. Social security and private transfers in developing countries: The case of Peru. The World Bank Economic Review 6, 155-169.

[10] Cox, D., Jakubson, G. 1995. The connection between public transfers and private interfamily transfers. Journal of Public Economics 57, 129-167.

[11] Cox, D., Rank, M.R. 1992. Inter vivos transfers and intergenerational exchange. Review of Economics and Statistics 74, 305-314.

[12] Hochguertel S., Ohlsson H. 2009. Compensatory inter vivos gifts. Journal of applied econometrics 24, 993-1023.

[13] Jensen, R. T. 2004. Do private transfers 'displace' the benefits of public transfers? Evidence from South Africa. Journal of Public Economics 88, 89-112.

[14] Juarez, L. 2009. Crowding out of private support to the elderly: Evidence from a demogrant in Mexico. Journal of Public Economics 93, 454-463.

[15] Kazianga H. 2006. Motives for household private transfers in Burkina Faso. Journal of Development Economics 79, 73-117.

[16] Laferrère, A., Wolff, F.C., 2006. Microeconomic models of family transfers. In: Kolm S.C., MercierYthier J. (Eds.), Handbook on the Economics of Giving, Reciprocity and Altruism. North- Holland, Amsterdam.

[17] Lai, M. S., Orsuwan, M. 2009. Examining the impact of Taiwan's cash allowance program on private households. World Development 37, 1250-1260.

[18] McDonald, John F. and Robert A. Moffitt. 1980. The Uses of Tobit Analysis. The Review of Economics and Statistics 62, 318-21.

[19] McGarry, K. 2000. Testing parental altruism: Implications of a dynamic model. NBER Working Paper 7593.

[20] McGarry, K., Schoeni, R.F. 1995. Transfer behavior in the Health and Retirement Study. Measurement and the redistribution of ressources within the family. Journal of Human Resources 30, $\mathrm{S} 185-\mathrm{S} 226$.

[21] Rosenzweig, M. R., Wolpin, K. I. 1994. Parental and public transfers to young women and their children. American Economic Review 84, 1195-1212.

[22] Schoeni, R. F. 2002. Does unemployment insurance displace familial assistance?. Public Choice 110, 99-119.

[23] Stock, J.H., Yogo, M., 2005. Testing for weak instruments in linear IV regression. In: Stock, J.H., Andrews, D.W.K., (Eds.), Identification and Inference for Econometric Models: A Festschrift in Honor of Thomas Rothenberg. Cambridge University Press, Cambridge, pp. 80-108. (Ch. 5). 
Table 1: Summary Statistics: Full Sample $(N=4,864)$

\begin{tabular}{l|cccc}
\hline \multicolumn{1}{c|}{ Parents' Characteristics } & Mean & Std. Dev. & Min & Max \\
\hline Parents receive social benefits (d) & & & & \\
Max age of parents & 0.423 & 0.494 & 0 & 1 \\
Parents receive pensions (d) & 71 & 11 & 50 & 95 \\
Parents took care of grandchildren (Age=3) (d) & 0.092 & 0.289 & 0 & 1 \\
The parent is unhealthy (d) & 0.022 & 0.146 & 0 & 1 \\
Education & 0.053 & 0.224 & 0 & 1 \\
Secondary (d) & & & & \\
College (d) & 0.144 & 0.351 & 0 & 1 \\
$\quad$ Respondents' Characteristics & 0.090 & 0.286 & 0 & 1 \\
Positive cash transfers to parents (d) & & & & \\
Monthly transferred to parents (\$NT thousands) & 0.685 & 0.464 & 0 & 1 \\
Age & 5.101 & 6.609 & 0 & 49.357 \\
Male (d) & 0.520 & 0.500 & 0 & 1 \\
Married (d) & 0.454 & 0.498 & 0 & 1 \\
\# of children under 18 & 0.787 & 1.023 & 0 & 4 \\
Education & & & & \\
Primary (d) & 0.112 & 0.316 & 0 & 1 \\
Secondary (d) & 0.331 & 0.471 & 0 & 1 \\
College (d) & 0.260 & 0.439 & 0 & 1 \\
Unhealthy (d) & 0.088 & 0.284 & 0 & 1 \\
Employed (d) & 1 & 0 & 0 & 1 \\
Total income (\$NT thousands) in 2002 & 688 & 912 & 0 & 20,036 \\
At least one parent is over 65 (d) & 0.675 & 0.469 & 0 & 1 \\
\# of living parents & 1.594 & 0.491 & 1 & 2 \\
Living with parents (d) & 0.330 & 0.470 & 0 & 1 \\
\hline
\end{tabular}

Source: Authors' calculations using the PSFD for the years 2002, 2004, and 2006. The top panel displays summary statistics of parents' characteristics for the full sample (respondents over the age of 25 with at least one living parent between the ages of 50 and 95) while the bottom panel displays summary statistics of respondents' characteristics. All variables are included as covariates in the estimation. All dollar amounts are translated to 2002 dollars based on the Taiwanese CPI. 
Table 2: Summary Statistics: Subsample

\begin{tabular}{|c|c|c|c|c|}
\hline & \multicolumn{4}{|c|}{ Parents Receive Social Benefits } \\
\hline & \multicolumn{2}{|c|}{$\begin{array}{c}\text { Yes } \\
N=2,056\end{array}$} & \multicolumn{2}{|c|}{$\begin{array}{c}\text { No } \\
N=2,808\end{array}$} \\
\hline & Mean & Std. Dev. & Mean & Std. Dev. \\
\hline Parents' Characteristics & & & & \\
\hline Parents receive social benefits $(\mathrm{d})$ & 1 & 0 & 0 & 0 \\
\hline Max age of parents & 76 & 8 & 66 & 11 \\
\hline Parents receive pensions $(\mathrm{d})$ & 0.036 & 0.188 & 0.133 & 0.340 \\
\hline Parents took care of grandkids $($ Age $=3)(\mathrm{d})$ & 0.008 & 0.091 & 0.032 & 0.175 \\
\hline The parent is unhealthy $(\mathrm{d})$ & 0.086 & 0.281 & 0.028 & 0.166 \\
\hline Education & & & & \\
\hline Secondary (d) & 0.060 & 0.238 & 0.205 & 0.404 \\
\hline College (d) & 0.049 & 0.216 & 0.119 & 0.324 \\
\hline Respondents' Characteristics & & & & \\
\hline Positive cash transfers to parents (d) & 0.721 & 0.449 & 0.660 & 0.474 \\
\hline Monthly transferred to parents ( $\$ \mathrm{NT}$ thousands) & 4.122 & 5.302 & 5.884 & 6.516 \\
\hline Age & 47 & 8 & 38 & 10 \\
\hline Male (d) & 0.512 & 0.500 & 0.526 & 0.499 \\
\hline Married (d) & 0.517 & 0.500 & 0.408 & 0.492 \\
\hline \# of children under 18 & 0.778 & 1.029 & 0.795 & 1.019 \\
\hline Education & & & & \\
\hline Primary (d) & 0.151 & 0.358 & 0.084 & 0.278 \\
\hline Secondary (d) & 0.304 & 0.460 & 0.351 & 0.477 \\
\hline College (d) & 0.159 & 0.366 & 0.335 & 0.472 \\
\hline Unhealthy (d) & 0.118 & 0.322 & 0.067 & 0.249 \\
\hline Employed (d) & 0.735 & 0.441 & 0.822 & 0.383 \\
\hline Total income (\$NT thousands) in 2002 & 663 & 1059 & 706 & 787 \\
\hline At least one parent is over $65(\mathrm{~d})$ & 0.954 & 0.210 & 0.470 & 0.499 \\
\hline \# of living parents & 1.458 & 0.498 & 1.694 & 0.461 \\
\hline Living with parents (d) & 0.263 & 0.440 & 0.379 & 0.485 \\
\hline
\end{tabular}

Source: Authors' calculations using the PSFD for the years 2002, 2004, and 2006. The top panel displays summary statistics of parents' characteristics (respondents over the age of 25 with at least one living parent between the ages of 50 and 95) while the bottom panel displays summary statistics of respondents' characteristics. 
Table 3: Extensive Margin Estimation Results

Dependent Variable $=1$ if respondent gives cash transfers to parent(s)

\begin{tabular}{|c|c|c|c|c|}
\hline & Probit & IV Probit & OLS & 2SLS \\
\hline Parents receive social benefits $(\mathrm{d})$ & $\begin{array}{c}0.150^{* * *} \\
(0.053)\end{array}$ & $\begin{array}{c}-1.500^{* * *} \\
(0.388)\end{array}$ & $\begin{array}{c}0.048^{* * *} \\
(0.017)\end{array}$ & $\begin{array}{c}-0.693^{* *} \\
(0.281)\end{array}$ \\
\hline Marginal Effect & $\begin{array}{c}0.047^{* * *} \\
(0.017)\end{array}$ & $\begin{array}{c}-0.509^{* * *} \\
(0.131)\end{array}$ & & \\
\hline First-stage coefficients on IV & & & & \\
\hline At least one parent over $65^{*} 2004$ & & $\begin{array}{c}0.174^{* * *} \\
(0.046)\end{array}$ & & \\
\hline At least one parent over $65^{*} 2006$ & & $\begin{array}{c}0.255^{* * *} \\
(0.049)\end{array}$ & & \\
\hline Number of observations & 4,864 & 4,864 & 4,864 & 4,864 \\
\hline
\end{tabular}

Estimation: Maximum Likelihood for Probit and IV Probit. Sample: Respondents between ages 25 and 65 (inclusive) with at least one living parent between the ages of 50 and 95 . The set of covariates in all estimations includes year dummies, a cubic polynomial in the age of the respondent, the maximum age of the parents, and the variables listed in Tables 1 and 2. Standard errors are listed in parenthesis and are clustered at the household level. The endogenous variable of interest is whether parents receive social benefits, and the instruments are the interactions of a dummy variable indicating that at least one parent is over the age of 65 and a dummy for each year after the program started (2003 and 2005). $* * *, * *, *$ Corresponds to statistical significance at the $1 \%, 5 \%$, and $10 \%$ level, respectively. 
Table 4: Intensive Margin Estimation Results

Dependent Variable $=$ Amount of cash transfers respondent gives to parent $(\mathrm{s})$

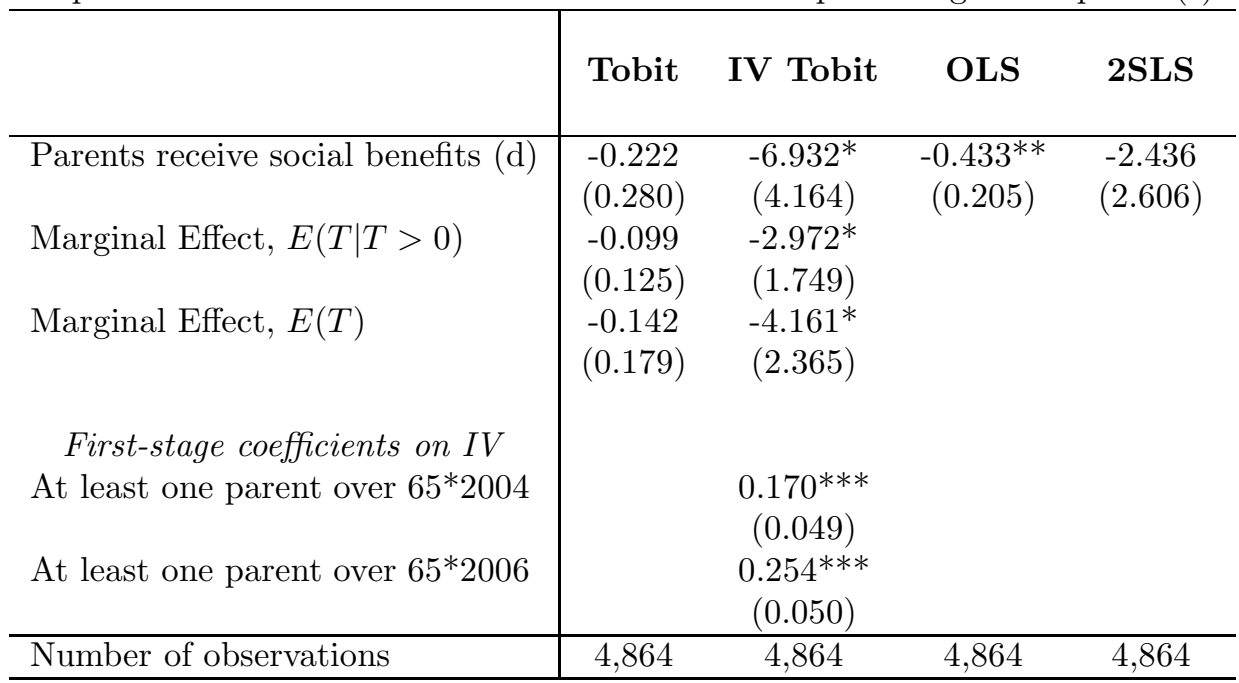

Estimation: Maximum Likelihood for Probit and IV Probit. Sample: Respondents between ages 25 and 65 (inclusive) with at least one living parent between the ages of 50 and 95. The set of covariates in all estimations includes year dummies, a cubic polynomial in the age of the respondent, the maximum age of the parents, and the variables listed in Tables 1 and 2. Standard errors are listed in parenthesis and are clustered at the household level. The endogenous variable of interest is whether parents receive social benefits, and the instruments are the interactions of a dummy variable indicating that at least one parent is over the age of 65 and a dummy for each year after the program started (2003 and 2005). $* * *, * *, *$ Corresponds to statistical significance at the $1 \%, 5 \%$, and $10 \%$ level, respectively. 
Table 5: Subsample Results

\begin{tabular}{l|cccc}
\hline & IV Probit & 2SLS & IV Tobit & 2SLS \\
\hline Parents receive social benefits (d) & -1.427 & $-0.507^{*}$ & -3.809 & -0.725 \\
& $(0.873)$ & $(0.273)$ & $(4.802)$ & $(2.798)$ \\
Respondent income in lower half of distribution interaction & -0.052 & 0.022 & 0.634 & 0.226 \\
& $(0.161)$ & $(0.064)$ & $(0.940)$ & $(0.660)$ \\
Parents education $\geq$ primary schooling interaction & 0.022 & 0.025 & -0.678 & -0.825 \\
& $(0.336)$ & $(0.095)$ & $(1.613)$ & $(1.107)$ \\
Living with parents interaction & $-0.486^{* * *}$ & $-0.142^{* *}$ & $-2.987^{* * *}$ & $-1.976^{* *}$ \\
& $(0.188)$ & $(0.068)$ & $(0.993)$ & $(0.796)$ \\
Respondent is male interaction & $0.576^{* * *}$ & $0.165^{* *}$ & 1.525 & 0.712 \\
& $(0.203)$ & $(0.064)$ & $(0.986)$ & $(0.698)$ \\
\hline
\end{tabular}

These are coefficient estimates associated with the interaction of an indicator for whether parents receive social benefits and various socio-demographic characteristics of interest. Sample: Respondents between ages 25 and 65 (inclusive) with at least one living parent between the ages of 50 and 95 . The set of covariates in all estimations includes year dummies, a cubic polynomial in the age of the respondent, the maximum age of the parents, and the variables listed in Tables 1 and 2. Standard errors are listed in parenthesis and are clustered at the household level. The endogenous variable of interest is whether parents receive social benefits, and the instruments are the interactions of a dummy variable indicating that at least one parent is over the age of 65 and a dummy for each year after the program started (2003 and 2005$) . * * *, * *, *$ Corresponds to statistical significance at the $1 \%, 5 \%$, and $10 \%$ level, respectively. 
Figure 1: Proportion of Parents Receiving Social Benefits: By Age and Year

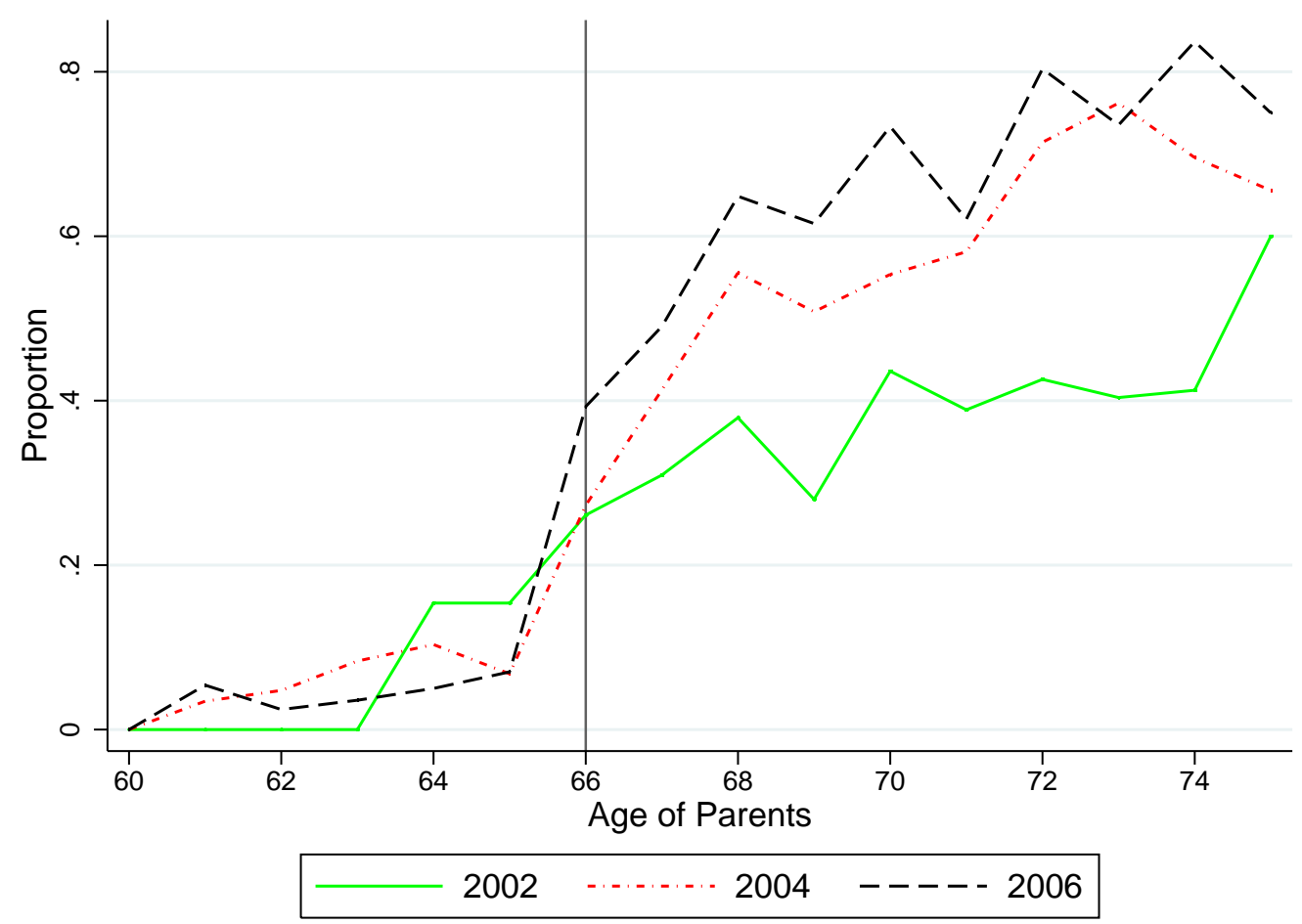

